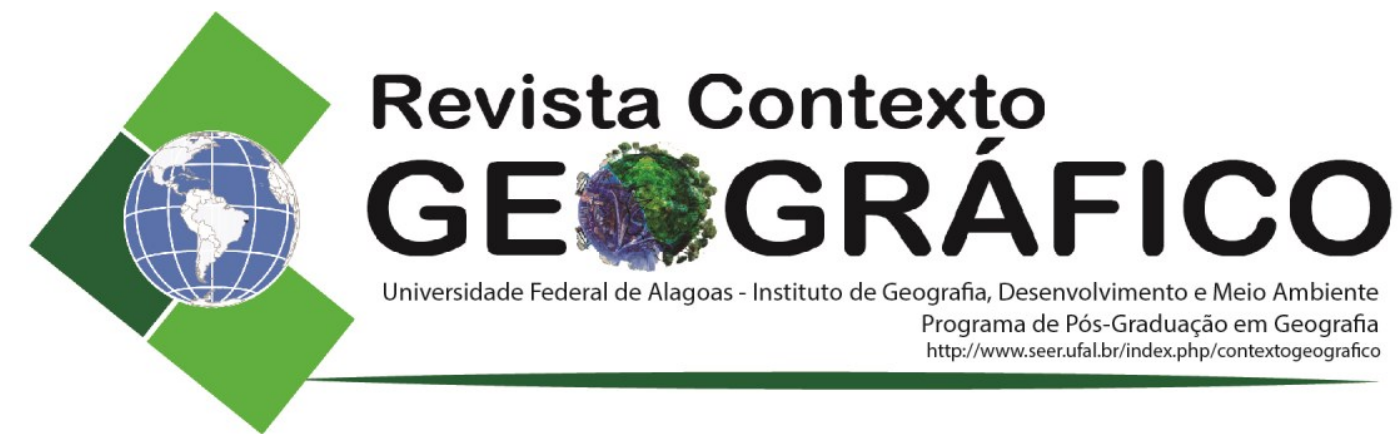

\title{
CARATERIZAÇÃO DA DINÂMICA DA LINHA DE COSTA NA ENSEADA DO PONTAL DE CORURIPE, LITORAL SUL DE ALAGOAS
}

\author{
Melchior Carlos do Nascimento \\ Universidade Federal de Alagoas, Instituto de Geografia, Desenvolvimento e Meio Ambiente, \\ Maceió, AL, Brasil \\ melchior.nascimento@igdema.ufal.br
}

Jose Antônio Cavalcante Cerqueira

Universidade Federal de Alagoas, Instituto de Geografia, Desenvolvimento e Meio Ambiente,

Maceió, AL, Brasil

jantcerqueira@igdema.ufal.br

Kinsey Pinto

Universidade Federal de Alagoas, Instituto de Geografia, Desenvolvimento e Meio Ambiente,

Maceió, AL, Brasil

kinsey.pinto@igdema.ufal.br

\begin{abstract}
RESUMO - Este trabalho apresenta um estudo sobre a dinâmica da linha de costa da enseada de Coruripe Pontal, Estado de Alagoas, nas últimas cinco décadas. A metodologia utilizada de imagens de satélite e aerotransportadas com eqüidistância temporal considerou principalmente fatores como a disponibilidade de imagens / fotografias aéreas no banco de dados e cobertura de nuvens sobre a região estudada. Os produtos gerados e as informações obtidas foram dadas através de sua manipulação no programa livre gvSIG 1.9. Através das medidas realizadas entre os litorais mapeados, observou-se que houve progradação no litoral entre os anos de 1965-1979 e de 1997-2008. Intervalos entre 1979-1988 e 1988-1997 foi encontrado erosão. Já a área de estudo é uma enseada onde a maré e as ondas estão presentes em faixas baixas, em razão da presença de recifes a três quilômetros além da costa. Trata-se de um estudo da escala espaço-temporal, embora existam diferenças entre as resoluções espaciais nas imagens, sendo que os resultados se mostraram satisfatórios por vários motivos como: a média de águas baixas apresentada nas imagens forneceu precisão suficiente para indicar a mudança de posição da linha de costa e processos de refração e ondas de surf, além da baixa disponibilidade de dados dessa natureza no Estado de Alagoas.
\end{abstract}

Palavras-chave: Imagem de satélite, Evolução temporal, Sensoriamento Remoto.

\section{CHARACTERIZATION OF THE DYNAMICS OF THE COASTLINE IN THE COURSE OF PONTAL DE CORURIPE, SOUTH COAST OF ALAGOAS}

\begin{abstract}
This paper presents a study about the line's dynamics of coast of the cove of Coruripe Pontal, State of Alagoas, over the past five decades. The used methodology of satellite images and airborne with temporal equidistance which considered mainly factors such as availability of images/aerial photographs in the database and cloud cover over the region studied. The products generated and the informations obtained had been given through its manipulation in the free program gvSIG 1.9. Through the measurements performed between the coastlines mapped, it was observed that there was progradation on the coastline between the years 1965-1979 and from 1997-2008. Intervals between 1979-1988 and 19881997 it was found erosion. Since the study area is a cove where the tide and waves are present at low ranges, in reason the presence of reefs three kilometers besides the coast. This is a study of time-space scale although differences exist between the spatial resolutions in the images, howewer results proved satisfactory several reasons like: the average low-water presented in the images provided sufficient accuracy to indicate the change in position of the shoreline and processes of refraction and surf wave, in adition to poor availability of data of this nature in the State of Alagoas.
\end{abstract}

Keywords: Satellite image, Time evolution, Remote sensing 


\section{INTRODUÇÃO}

O dinâmico processo entre as águas do oceano e o continente, na maioria das vezes, transforma as regiões costeiras em área de grande incidência de energia, favorecendo ao longo do tempo as mudanças espaciais na morfologia das linhas de costa. Para Pereira (2010, p. 1) as características de qualquer litoral foram e são impostas pela atuação dos processos de geodinâmica interna e externa ao longo do tempo geológico. Embora sejam admitidos diversos fatores naturais como responsáveis pelos processos de erosão costeira, a intervenção humana tem promovido consequências direta e indireta quanto ao mudanças da linha de costa.

Conceitualmente a linha de costa é simplesmente o limite entre o continente e o mar (GONÇALVES et al, 2010, p. 2), correspondendo a porção adjacente ao mar onde não há efetiva ação marinha no alcance máximo das ondas, concretizando-se pela presença de falésias, no limite entre a vegetação e a praia, ou nos costões rochosos, ou por qualquer outra feição que marque o início da área continental (SUGUIO, 1992).

Para Santos et al $(2014$, p. 3), atualmente o traçado e a posição da linha de costa dependem de fatores interativos e retroativos, dos quais se destacam o forçamento oceanográfico (ondas, marés, correntes costeiras, sobre-elevação meteorológica, nível médio do mar), os sedimentos (natureza, dimensão, disponibilidade), o contexto geomorfológico (incluindo praias, arribas, estuários, lagoas e ilhas barreira) e a intervenção antrópica. É importante ressaltar, que entre os diversos fatores responsáveis pelas alterações em linhas de costa, as ondas, as marés, os ventos, a batimetria, são os que mais influenciam nesse processo.

A enseada do Pontal do Coruripe, área alvo deste estudo, vem ao longo do tempo sofrendo constantes modificações em sua morfologia e isto se deve, predominantemente, por ser uma zona de contato entre o oceano e o continente. Por ser parte componente do estuário do rio Coruripe, que se apresenta em bom estado de conservação, é uma área que possui relevante interesse ecológico e com altíssimo potencial turístico, em virtude da singularidade do local. Além disso, a região também tornou-se durante um tempo alvo do interesse da indústria de manufatura de navios e plataformas marinhas, por possuir águas abrigadas da incidência das ondas com grande energia cinética.

A partir dos aspectos naturais e antropogênicos, os estudos destinados em avaliar as dinâmicas costeiras na referida área podem oferecer informações essenciais às tomadas de decisões quanto aos impactos decorrentes das atividades humanas na região. Nesta perspectiva, o uso integrado de geoprocessamento e sensoriamento remoto tem se destacado no monitoramento costeiro, especialmente na previsão das dinâmicas evolutivas.

Assim sendo, o presente estudo teve como objetivo principal avaliar a dinâmica da linha de costa ao longo das últimas cinco décadas, observando as escalas tempo e espaço na evolução das formas do relevo. Braga (2009), afirma que estas escalas são fatores que devem ser ponderados no processo de compreensão da modelagem de um determinado relevo, levando em consideração a litosfera como um sistema que mantém a troca de energia e matéria a fim de se manter em constante equilíbrio, principalmente em áreas com interface praial.

Estudos desta natureza, que tem como finalidade a mensuração sazonal da linha de costa, encontram problemas pela ausência de série de dados representativos, principalmente para datas remotas.

A justificativa para a adoção do método do estudo, através da utilização de imagens orbitais e aerotransportadas se dá por considerá-lo o marco zero para este tipo de análise no município de Coruripe, visto que outros métodos conhecidos não poderiam ser utilizados por exigir monitoramento contínuo ao longo das décadas passadas. Logo, os cotejos entre as informações 
contidas em documentos cartográficos existentes fornecem uma base para o conhecimento das tendências evolutivas de um determinado local. Para Mota (2009) a delimitação do padrão espaço-temporal pode auxiliar na compreensão do histórico evolutivo da paisagem.

De acordo com Oliveira $(2005$, p. 29) desde cedo que a utilização de fotografias aéreas teve forte aceitação por todos os que se dedicam a estudos da dinâmica costeira, fruto das potencialidades inerentes a uma imagem, que regista para um determinado momento e espaço as características geomorfológicas, logo relacionáveis com os processos que caracterizam a evolução destes ambientes litorais. Souto (2009) assevera que o monitoramento do ambiente costeiro através de séries temporais de imagens de satélite, permite acompanhar as modificações da morfologia costeira através do estudo da posição da linha de costa.

\section{MATERIAIS E MÉTODOS}

\section{Localização e caracterização da área}

A enseada alvo deste estudo possui uma extensão aproximada de dois quilômetros e está situada na porção central do município de Coruripe. Estende-se entre as coordenadas geográficas $36^{\circ} 09^{\prime} 01^{\prime \prime} \mathrm{W}, 10^{\circ} 09^{\prime} 27^{\prime}$ 'S e $36^{\circ} 08^{\prime} 08^{\prime \prime} \mathrm{W}, 10^{\circ} 09^{\prime} 38^{\prime \prime} \mathrm{S}$; limitando-se ao norte com manguezal, ao sul com o oceano atlântico, a leste com o povoado Pontal de Coruripe e a oeste com a foz do rio que dá nome ao município (Figura 1).

Figura 1 - Localização do Pontal do Coruripe, município de Coruripe, Alagoas, Brasil

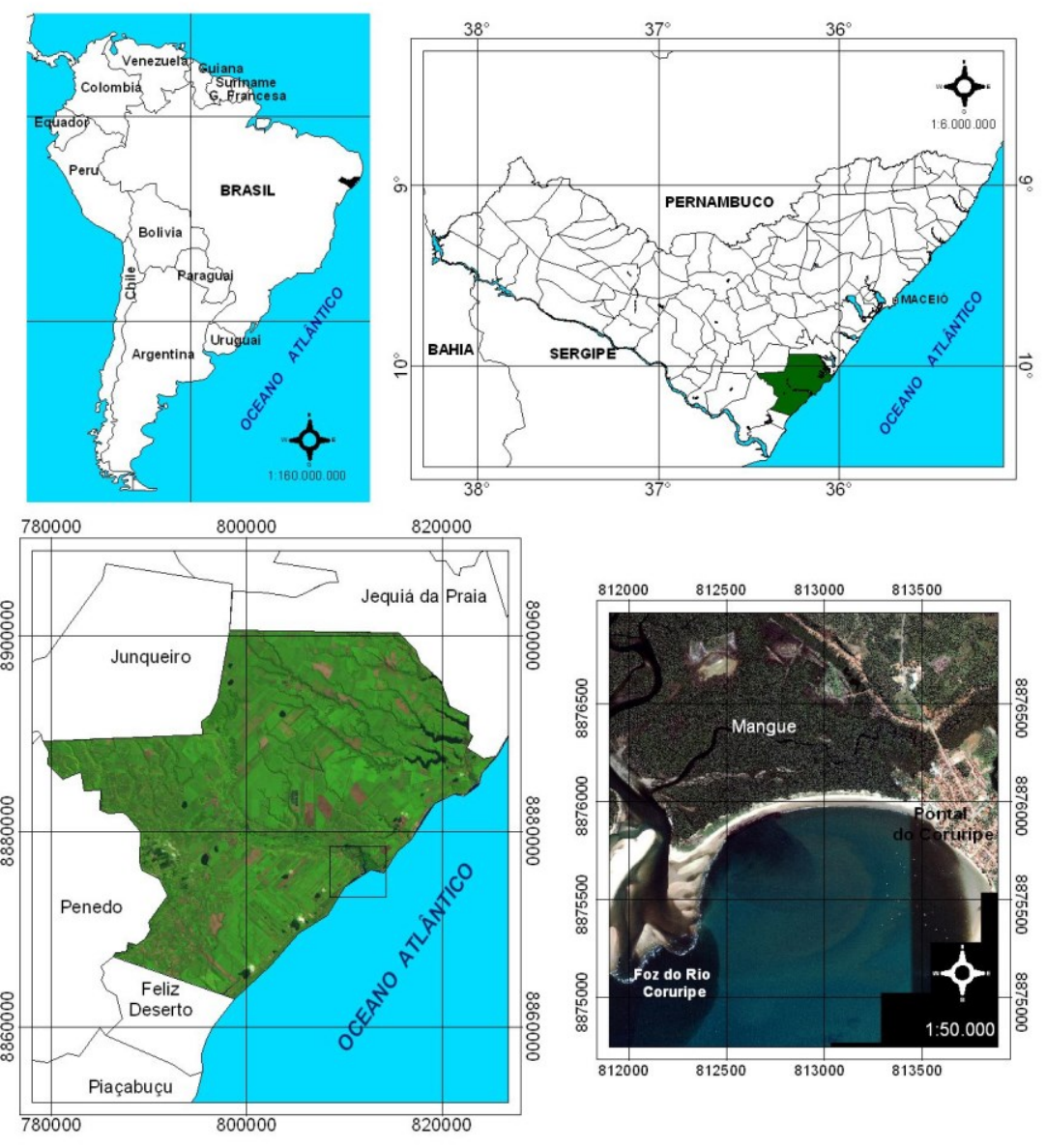


A área de estudo encontra-se totalmente inserida no compartimento litoestrutural da Província Costeira, posicionada na margem direita do rio Coruripe, proximidades do povoado Barreiras (Sul) e Pontal do Coruripe (Norte). A Província Costeira na área do entorno compreende um pacote Sedimentar de idade cenozóica (quaternárias e terciárias) e Paleo-mesozóicas (cretáceas) da Bacia Sedimentar Alagoas (Almeida et al., 1977; Feijó, 1990). Na área em apreço, são observados depósitos quaternários (arenosos e areno-argilosos) representados pelos Sedimentos de Praia e Aluvião. Estes sedimentos encontram-se associados à Planície Costeira, onde são observadas restingas, cordões arenosos, cristas praias de baixios costeiros, terraços marinhos, fluviais, flúvio-marinhos e flúvio-lacustres (Goes, 1979; Nou et. al., 1983; Dantas, 1986).

No decorrer do quaternário ocorreram às transgressões e regressões marinhas, responsáveis pela alteração do perfil na linha de costa e equilíbrio dos rios, intensificado a abrasão e erosão, ocorrendo o aprofundamento dos vales. Os períodos transgressivos acarretaram a invasão dos vales e promovendo a evolução de "rias" e alargamento dos leitos. Estes fatos são comprovados através de estudos realizados nas planícies costeiras da faixa central do estado de Alagoas por Lima (1990) e dos estados da Bahia, Sergipe e Sul de Alagoas por Barbosa (1986), que identificaram três episódios transgressivos denominados de transgressão mais antiga, penúltima e última transgressão.

A avaliação dinâmica atual da Planície Costeira na área em apreço, segundo Nou et. al., (1983) está relacionada aos modelados de acumulação marinha e flúvio-marinha, apresentando-se instáveis e de intensidade muito forte, formado por sedimentos arenosos, areno-argilosos, argilosos, às vezes contendo cascalhos. Nestes ambientes, a cobertura vegetal é descontínua, predominando a cultura do coco-da-baía associado às formações pioneiras marinhas: restingas herbáceas de praia e mangues (Gonçalves e Orlandi, 1983; Sarmento e Chaves, 1986).

Os processos geomorfológicos predominantes dos modelados de acumulação estão representados pelo escoamento concentradas com cheias periódicas provocadas pela variação do regime hidrológico sujeito a influência de clima úmido a sub-úmido Nou et. al. (1983). Localmente predomina escoamento superficial em forma de enxurradas e abrasão marinhas somadas a ação das águas de inundação provocadas pelas variações dos regimes hidrológicos e das marés causando sedimentação (op. cit. 1983). Essa condição é influenciada ainda, pelas características edáficas da área em apreço, na qual é marcante a presença de Neossolos Quartzarênicos (RQ) que ocorrem paralelas à linha do litoral, numa faixa estreita, representados por Areias Quartzosas Marinhas profunda não-hidrmórficas associadas a Espodossolos Humilúvicos (EK), ambos apresentam horizonte A fraco, moderado e proeminente, de textura arenosa, ambos fase campo e floresta perenifólia de restinga relevo plano e outra simplesmente pela presença de Areias Quartzosas Marinhas Distróficas (dunas e cristas praiais), fase relevo plano e suave (Alagoas, 2010).

\section{Materiais utilizados}

Foram utilizadas cinco fontes de dados obtidas em levantamento cartográfico existente em bases de dados de diversas organizações públicas, correspondentes às últimas cinco décadas de registro para a área em questão e selecionadas com base numa equidistância temporal que considerou principalmente fatores como disponibilidade de imagens/aerofotos em base de dados e cobertura de nuvens sobre a região estudada. São apresentadas a seguir em ordem cronológica tais dados:

$\rightarrow 1965$ - Petrobras. Levantamento aéreo da bacia Sergipe-Alagoas. Fls. 63-4-1. Escala 1:25.000 (restituída). Fonte do mapeamento: Cobertura Aerofotogramétrica da Cruzeiro do Sul S/A. Escala de origem 1:60.000. 
$\rightarrow 1979$ - Imagem do satélite Landsat 3. Sensor MSS. Escala 1:100.000. Resolução espacial: 79 metros. Data da Passagem: 26/03/1979. Órbita/Ponto: 230/67. Composição R3G4B5.

$\rightarrow 1988$ - Imagem do satélite Landsat 5. Sensor TM. Escala 1:100.000. Resolução espacial 30 metros. Data da Passagem: 05/06/1988. Órbita/Ponto: 214/67. Composição R3G4B5.

$\rightarrow 1997$ - Petrobras. Cobertura Aerofotogramétrica da Cruzeiro do Sul S/A. Escala:1:60.000.

$\rightarrow 2008$ - Imagem multifusionada do satélite Ikonos 2. Sensor CCD. Escala 1:5.000. Resolução espacial 1 metro. Datas das passagens: 24/07/2006, 04/08/2006 e 26/08/2006.

\section{Geração da base de dados}

Esta etapa consistiu no georreferenciamento dos dados adotando o sistema de projeção UTM, fuso 24 e Datum SAD-69, tomando como referência a carta topográfica do IBGE folha SC-24-Z-B-III-2. Em seguida, os dados sofreram recortes nos limites do retângulo baseados nas seguintes coordenadas: 810.000 e 816.000 de longitude Este e 8.874 .000 e 8.878 .000 de latitude Norte, compreendendo uma área estudada de $24 \mathrm{~km}^{2}$. Por fim, houve a vetorização em tela das linhas de costa, sendo os arquivos salvos em formato shapefile. Todos os procedimentos aqui descritos foram realizados com o uso do aplicativo gvSIG 1.9..

\section{Procedimentos adotados}

Para se obter os resultados, se fez necessário marcar dez pontos de controle (PC), com fins de mensuração. Estes foram distribuídos a cada cem metros ao longo dos mil metros de costa que interessam à indústria. Em seguida, foram registradas as distâncias nos PC entre cada cena correspondente a uma década.

\section{RESULTADOS E DISCUSSÃO}

A partir das mensurações realizadas nas variações da linha de costa das imagens, pode-se observar que houve avanço na linha de costa entre os anos de 1965 a 1979 e entre 1997 a 2008 (Tabela 1). Já entre as variações cotejadas nos intervalos de 1979 a 1988 e de 1988 a 1997 verificou-se recuo da linha de costa (Figuras 2 e 3 ).

Tabela 1 - Variação das distâncias das linhas de costa ao longo das últimas cinco décadas, com base nas mensurações mínimas, médias e máximas

\begin{tabular}{c|c|c|c|c}
\hline \multirow{2}{*}{ Distância } & \multicolumn{4}{|c}{ Período } \\
\cline { 2 - 5 } & $\mathbf{1 9 6 5 - 1 9 7 9}$ & $\mathbf{1 9 7 9 - 1 9 8 8}$ & $\mathbf{1 9 8 8 - 1 9 9 7}$ & $\mathbf{1 9 9 7 - 2 0 0 8}$ \\
\hline Média & 21 & -35 & -39 & 31 \\
Máxima & 46 & -77 & -57 & 50 \\
Mínima & 11 & -16 & -10 & 21 \\
\hline
\end{tabular}

Figura 2 - Variação da linha de costa ao longo das últimas cinco décadas, com base nas mensurações mínimas, médias e máximas 


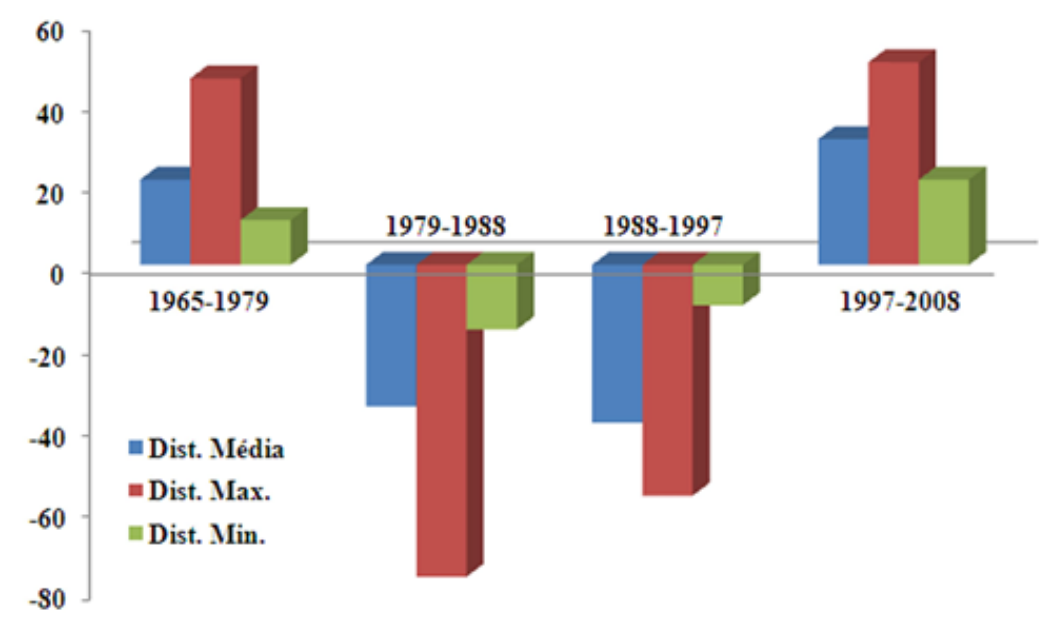

Figura 3 - Registro das linhas de costa ao longo das últimas cinco décadas

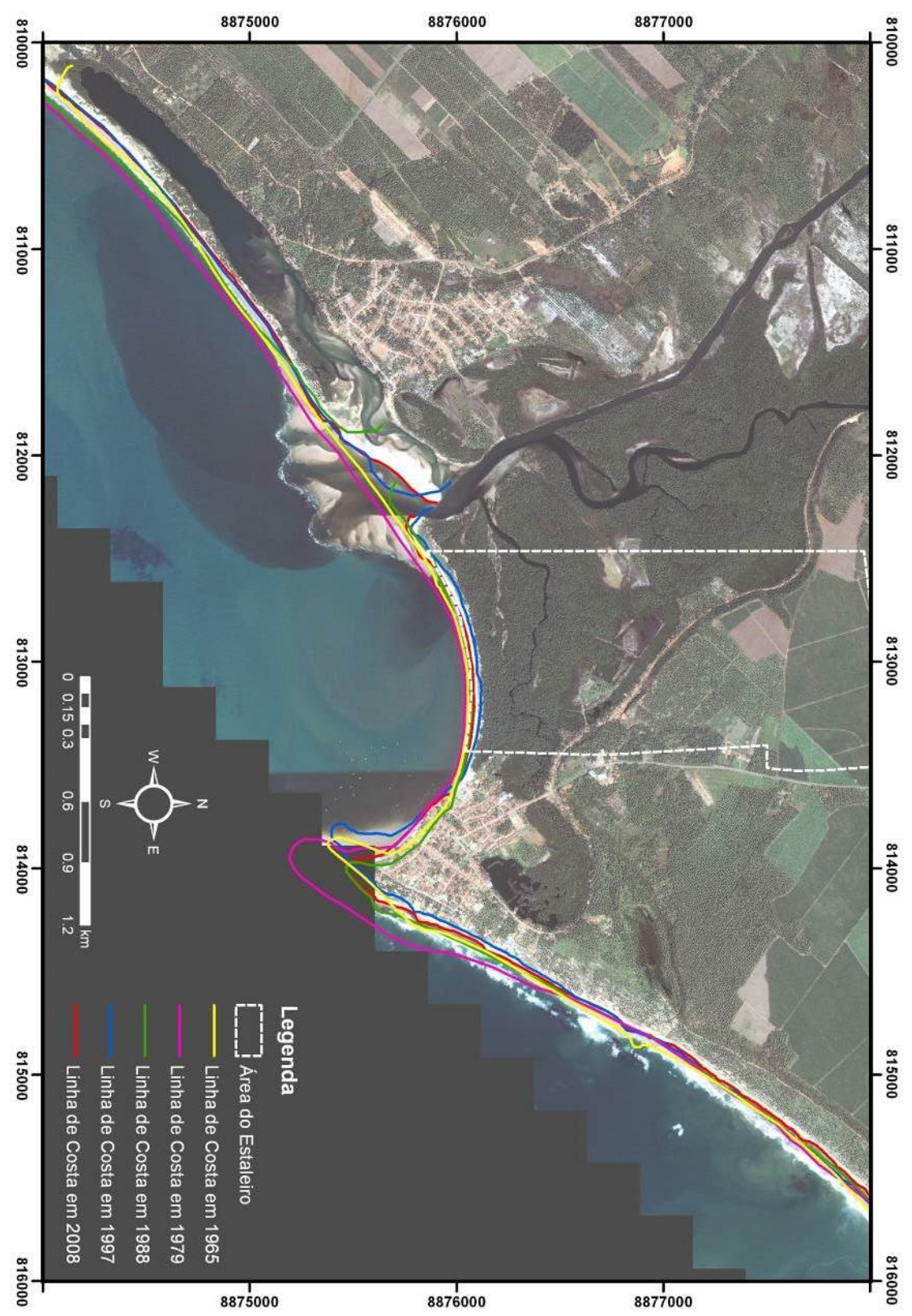




\section{Cotejo entre os anos de 1965 e 1979}

Com base nas mensurações realizadas nos planos de informação dos respectivos anos, verificou-se que houve incremento de sedimento, promovendo a progradação da linha de costa (Figuras 4 e 5). No trecho que compreende a área de interesse para a instalação do estaleiro EISA, de aproximadamente um quilômetro de largura, foram medidas as distâncias em entre as linhas de costa dos anos de 1965 e 1979 em dez pontos de interesse, no qual se constatou flutuação das medidas; de sorte que a distância média obtida foi de apenas +21 metros, sendo que houve registro máximo de +46 metros e mínimo de +11 metros.

Figura 4 - Distâncias registradas entre as linhas de costa dos anos de 1965 e 1979

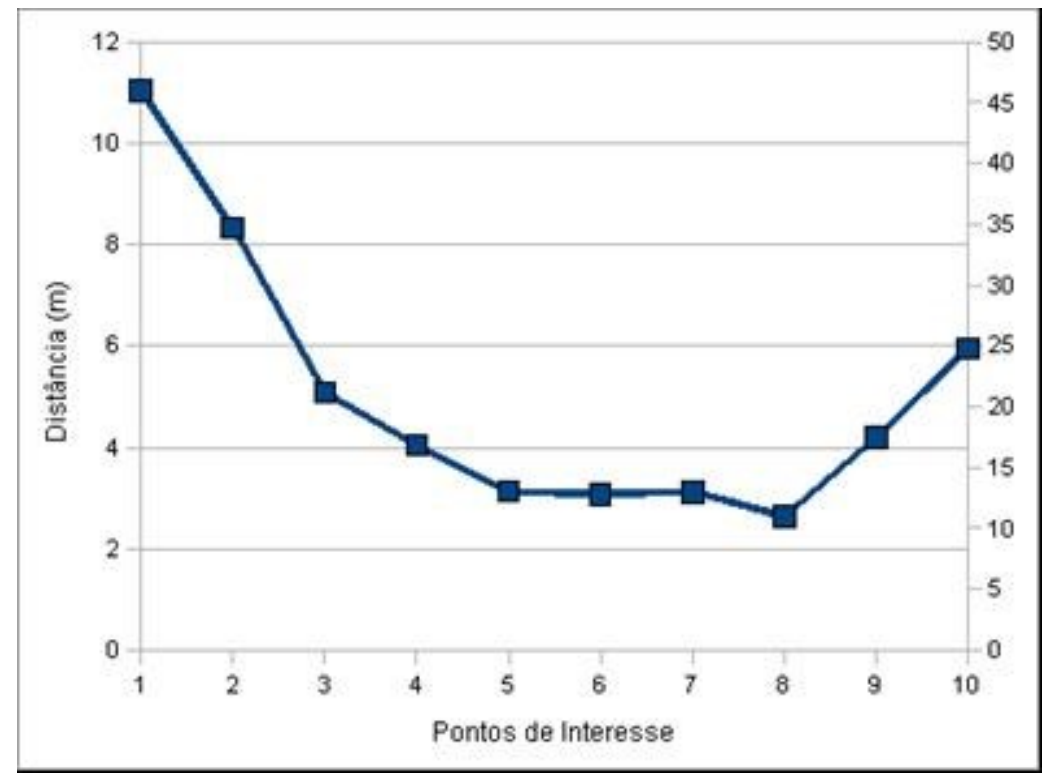

Figura 5 - Morfologia da linha de costa para os anos de 1965 e 1979

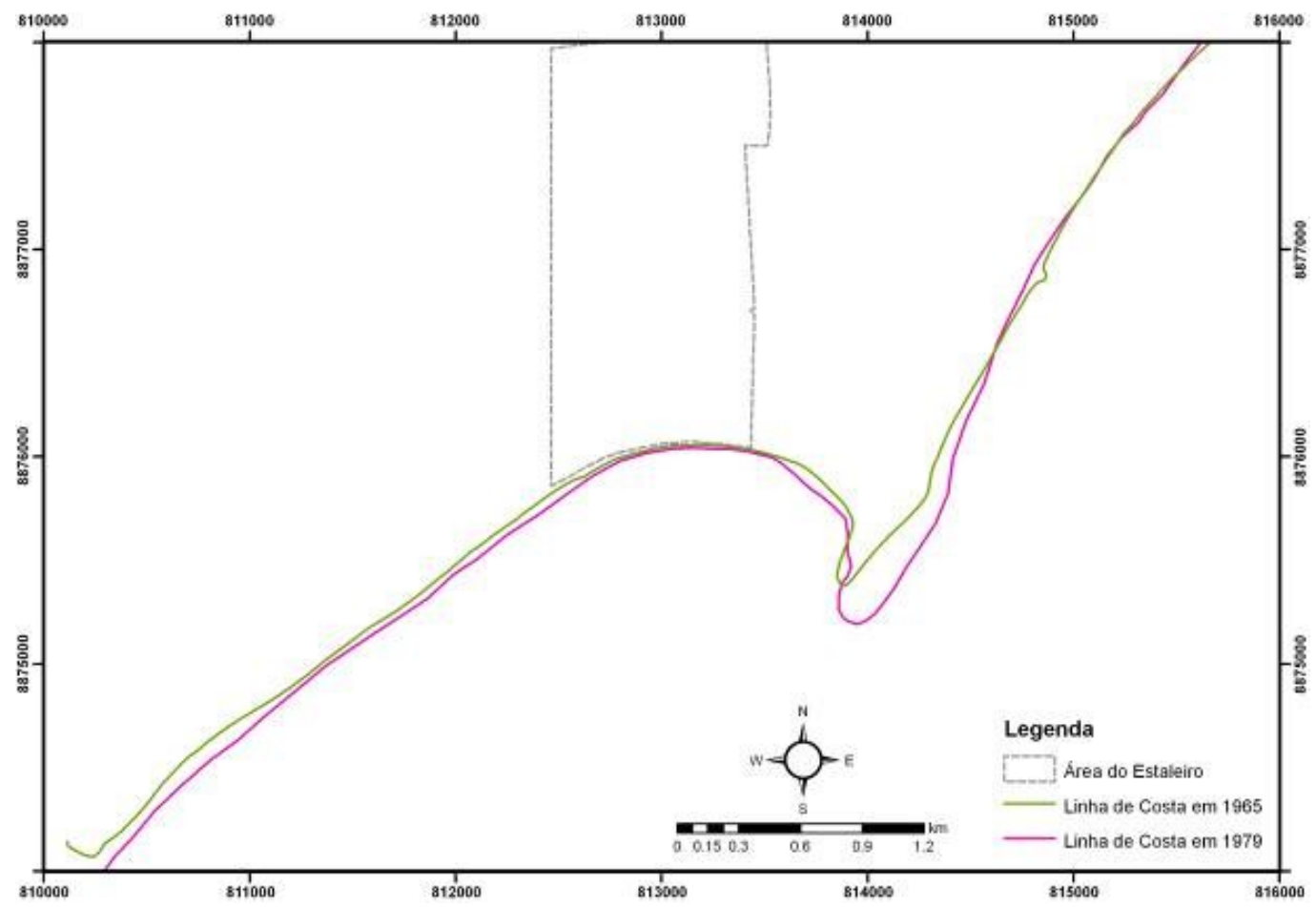




\section{Cotejo entre os anos de 1988 e 1997}

Aqui, a variação mensurada apresenta uma perda de sedimentos na linha costeira. A distância média entre as linhas dos anos em questão é de -39 metros, com distância máxima de -57 metros e mínima de -10 metros (Figuras 6 e 7 ).

Figura 6 - Distâncias registradas entre as linhas de costa dos anos de 1988 e 1997.

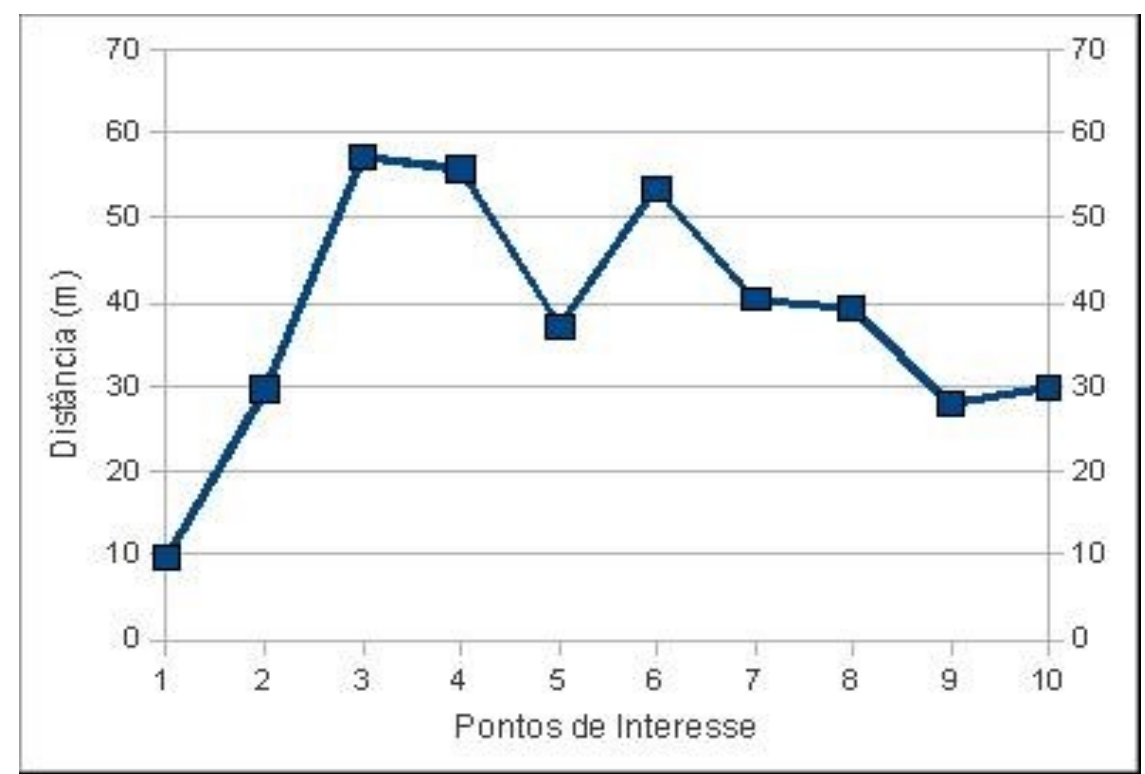

Figura 7 - Morfologia da linha de costa para os anos de 1988 e 1997.

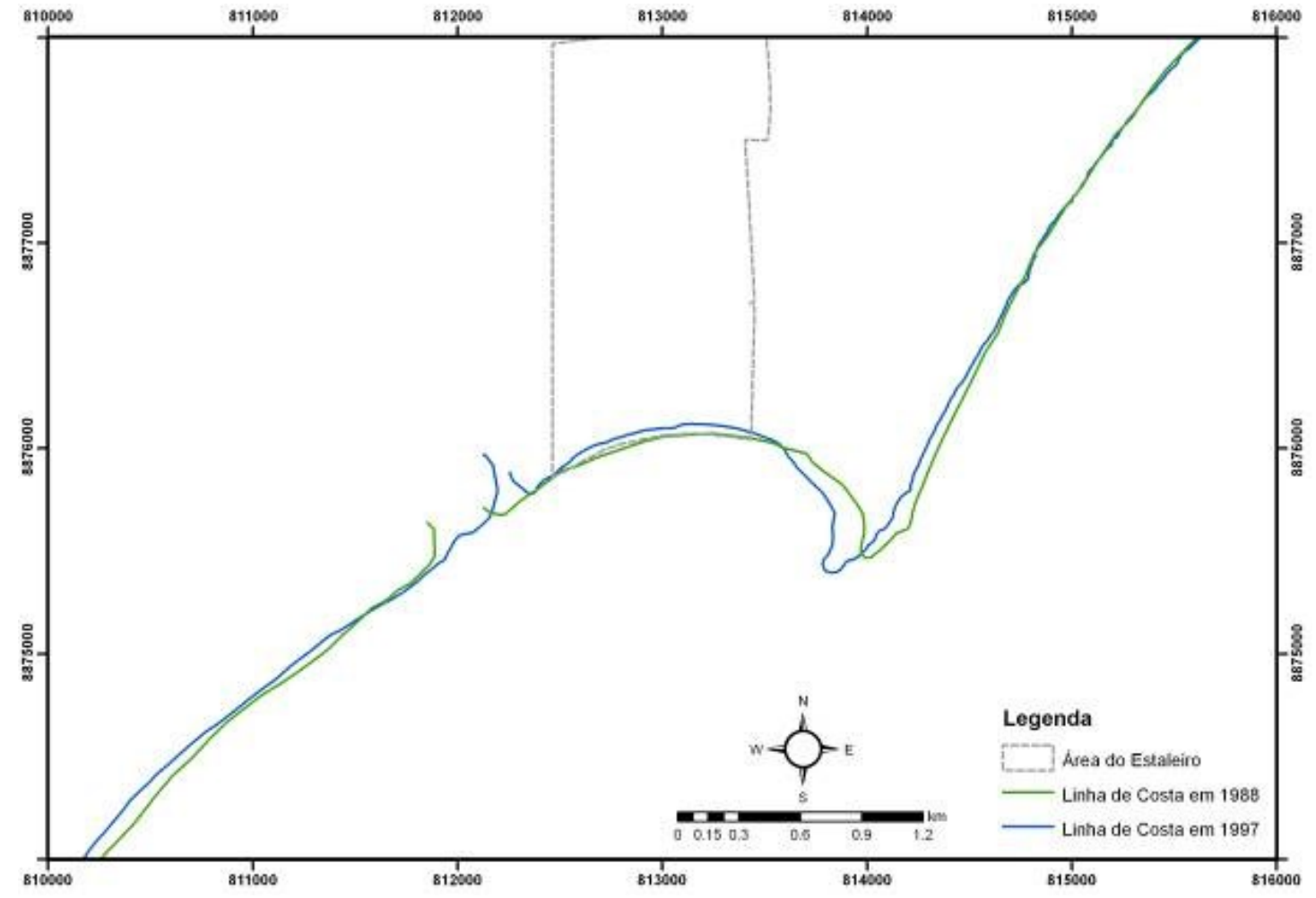




\section{Cotejo entre os anos de 1997 e 2008}

Nesta comparação, observando as Figuras 10 e 11 é possível verificar que a linha costeira tornou a movimentar-se em direção ao oceano, num processo de engordamento médio +31 metros, com oscilações máxima e mínima de +50 metros e +21 metros respectivamente.

Figura 10. Distâncias registradas entre as linhas de costa dos anos de 1997 e 2008

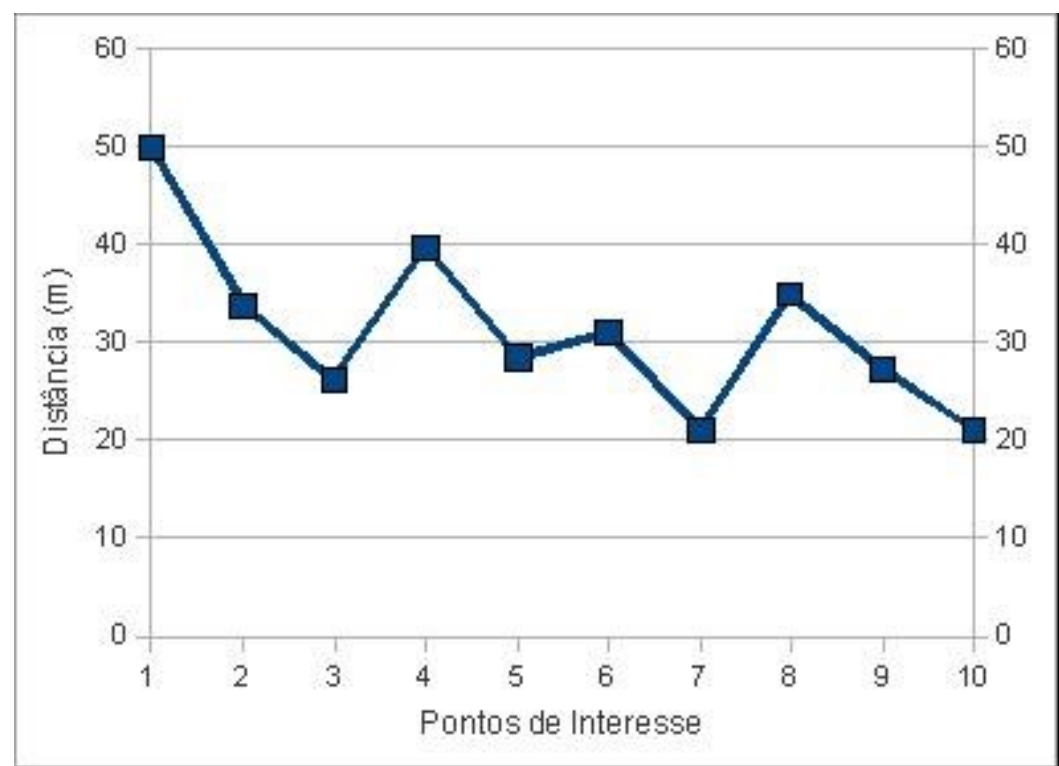

Figura 11. Morfologia da linha de costa para os anos de 1997 e 2008

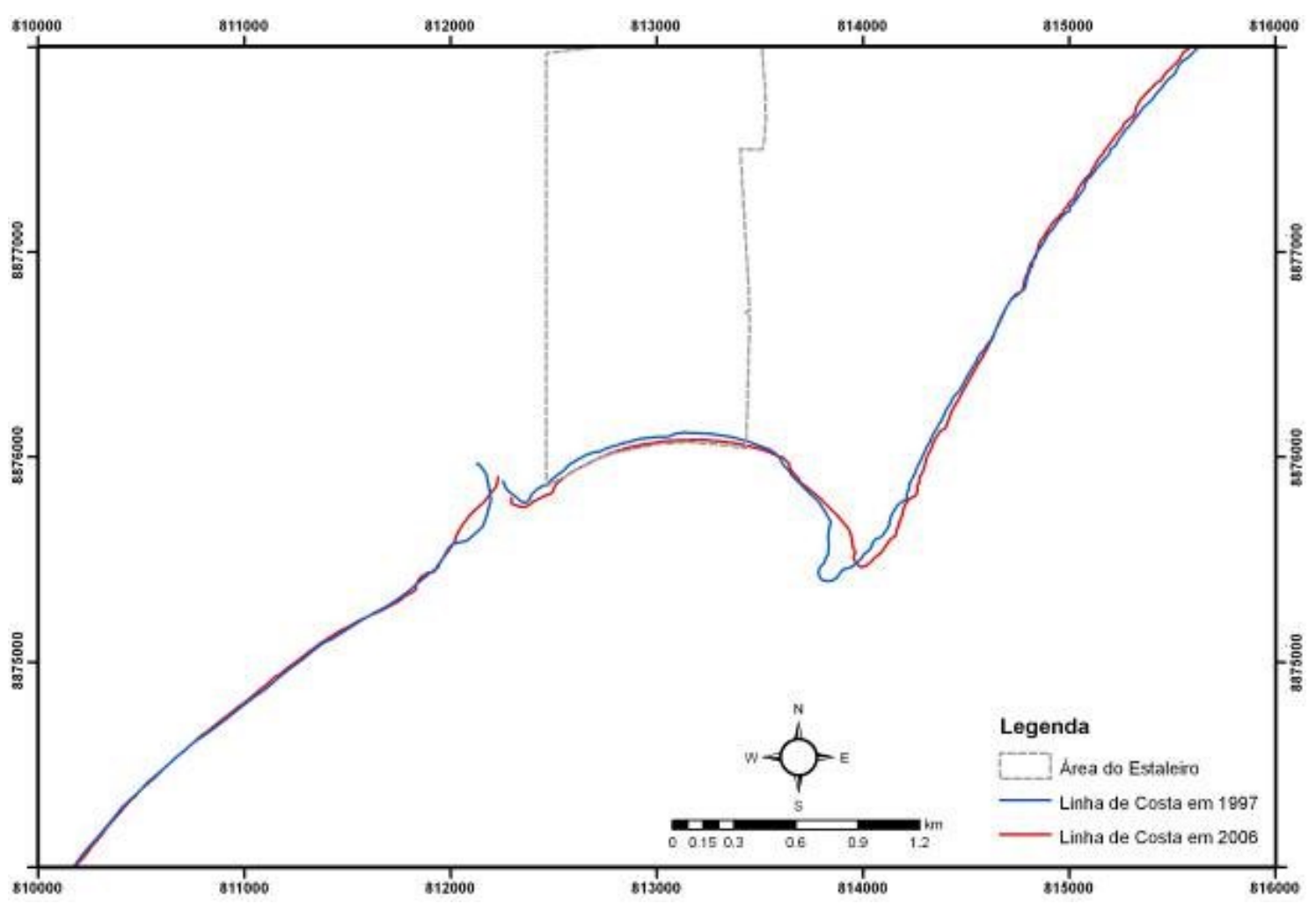




\section{CONSIDERAÇÕES FINAIS}

Em zonas costeiras onde a maré apresenta amplitudes pequenas a médias, como como ocorre na enseada do Pontal de Coruripe, o método que faz uso de imagens de satélites e/ou de fotografias aéreas são os mais recomendados, mesmo havendo diferenças entre as resoluções espaciais das imagens, visto que a adoção do nível médio de baixa-mar fornece uma precisão suficiente para indicar a variação da posição da linha de costa, assim como para os processos de refração e arrebentação das ondas.

Por ser um estudo de escala espaço-temporal, a seleção das datas das imagens em intervalos equidistantes, representadas pelas décadas de 1960, 1970, 1980, 1990 e 2000 mostraram-se satisfatórias, em decorrência da precária disponibilização desses dados para e no Estado de Alagoas.

\section{REFERÊNCIAS}

ALAGOAS, Secretaria de Estado da Agricultura e do Desenvolvimento Agrário. Zoneamento Agroecológico do Estado de Alagoas - ZAAL: Mapa de Zoneamento Agroecológico, formato shapefile, Esc.: 1:100.000, 2010.

ALMEIDA, F.F.M. de et al. Províncias estruturais brasileiras. In: Simpósio de Geologia do Nordeste, $8^{\circ}$ atas da Sociedade Brasileira de Geologia-núcleo Nordeste. Boletim 6. Campina Grande - PB, p. 363-391, 1977.

BARBOSA, L. M.. Quaternário Costeiro no Estado de Alagoas: Influências das variações do nível do mar. Salvador: UFBA, 1986. 58 p.. Dissertação de Mestrado em Geociências. UFBA, 1986.

BRAGA, M.. Evolução Geomorfológica e seus Aspectos. Disponível em $<$ http://br.geocities.com/uel_geomorfologia2/artigodirunomarcelobraga.htm>. Acesso em: 15 jun. 2009.

DANTAS, J.R.A., et al. Mapa Geológico do Estado de Alagoas. Texto Explicativo. Recife: DNPM/SUDENE/EDRN-AL, 1986. 90 p.

FEIJÓ, F. J. Bacia de Sergipe Alagoas. Rio de Janeiro. Geociências: Revista da PETROBRÁS, Rio de Janeiro, 8(1): 149 - 161, jan./mar., 1994.

GOES, M. H. de B. Ambientes Costeiros do Estado de Alagoas. 3 v. Rio de Janeiro, 1979, 397 f. Dissertação (Mestrado em Geografia) - Universidade Federal do Rio de Janeiro, 1979.

GONÇALVES, L.M.C.; Orlandi, R.P. Vegetação: as regiões fitoecológicas, sua natureza e seus recursos econômicos - estudo fitogeográfico. In: Brasil, Ministério das Minas e Energia, Secretaria Geral, PROJETO RADAMBRASIL. Folhas SC. 24/25 Aracaju/Recife. Rio de Janeiro, 1983. p. 573-652. (Série: LRN. V. 30).

GONÇALVES, R. M.; KRUEGER, C. P.; COELHO, L. S.; HECK, B. Monitoramento geodésico da linha de costa com o emprego do GNSS. In: III Simpósio Brasileiro de Ciências Geodésicas e Tecnologias da Geoinformação. Anais do Simpósio Brasileiro de Ciências Geodésicas e Tecnologias da Geoinformação, Recife-PE, 2010, p. 1 - 5.

LIMA, I. F. Maceió a cidade restinga: contribuição ao estudo geomorfológico do litoral alagoano. 2 ed. Maceió: EDUFAL, 1990. 255p.

NOU, E.A.V.; Bezerra, L.M.M.; DANTAS, M. Geomorfologia. In: Brasil, Ministério das Minas e Energia, Secretaria Geral, PROJETO RADAMBRASIL. Folhas SC. 24/25 Aracaju/Recife. Rio de Janeiro: DIPUB/RADAMBRASIL, 1983. p. 347-443 (Série: LRN. V. 30).

PEREIRA, C. A. S. Risco de Erosão para Diferentes Cenários de Evolução do Litoral de Aveiro. Portugal: Universidade de Aveiro/Departamento de Engenharia Civil, 2010. Dissertação (Dissertação de Mestrado), Universidade de Aveiro/Departamento de Engenharia Civil, 2010, 78 p.

SANTOS, F. D.; LOPES, A. M.; MONIZ, G.; RAMOS, L. TABORDA, R. Gestão da Zona Costeira: o desafio da mudança. Portugal: Relatório (Relatório do Grupo de Trabalho do Litoral), 2014, 237 p.

SARMENTO, A. C.; Chaves, L.F.C. Vegetação do Estado de Alagoas: as regiões fitoecológicas, sua natureza e seus recursos econômicos - estudo fitogeográfico. In: Brasil, Ministério das Minas e Energia, Secretaria Geral, PROJETO RADAMBRASIL; Alagoas, Empresa de Desenvolvimento dos Recursos Naturais. Salvador; Maceió, A1985. 68 p. Mimeografado. 
SUGUIO, K., 1992. Dicionário de geologia sedimentar e areas afins, in Dicionário de geologia sedimentar e areas afins, B. Brasil, Editor., BCD União de Editoras: Rio de Janeiro. p. 1217. 